Article

\title{
Examining the Relationship between Hukou Status, Perceived Neighborhood Conditions, and Fear of Crime in Guangzhou, China
}

\author{
Fengrui Jing ${ }^{1,2} \mathbb{D}$, Lin Liu ${ }^{3,4, * \mathbb{C}}$, Suhong Zhou ${ }^{1,2}$ and Guangwen Song ${ }^{4}$ \\ 1 School of Geography and Planning, Sun Yat-sen University, Guangzhou 510275, China; \\ jingfr@mail2.sysu.edu.cn (F.J.); eeszsh@mail.sysu.edu.cn (S.Z.) \\ 2 Guangdong Provincial Engineering Research Center for Public Security and Disaster, \\ Guangzhou 510275, China \\ 3 Department of Geography, University of Cincinnati, Cincinnati, OH 45221-0091, USA \\ 4 Center of GeoInformatics for Public Security, School of Geographical Science and Remote Sensing, \\ Guangzhou University, Guangzhou 510006, China; songgwen@126.com \\ * Correspondence: lin.liu@uc.edu
}

Received: 4 October 2020; Accepted: 16 November 2020; Published: 18 November 2020

\begin{abstract}
Fear of crime can lead to lower satisfaction with life and subjective well-being. The indicators of fear of crime vary from the social and cultural context, and the hukou (household registration) status causes unequal rights between local hukou and non-local hukou residents in China. To improve people's perception of safety, this study takes hukou as an indicator of social vulnerability and examines the relationship between hukou, perceived neighborhood conditions, and fear of crime in China. A binary logistic regression model was used to analyze the 1727 residents garnered from the 2016 Project on Public Safety in Guangzhou Neighborhoods (PPSGN) in Guangzhou, China. The results show that women, victimization experience, physical and social disorder, and neighborhood policing are associated with residents' fear of crime. Although hukou status has no statistically significant effect on fear of crime, hukou status significantly moderates the influence of perceived neighborhood conditions on fear of crime. That is, perceived neighborhood conditions' effects on fear are conditional on one's hukou status: non-local hukou, perception of the social disorder has more of the detrimental effect on fear, and perception of social integration has less of the helpful effect on fear. In sum, this study adds to the international literature by revealing the conditional effect of the hukou on fear in a Chinese city.
\end{abstract}

Keywords: fear of crime; hukou status; perceived neighborhood conditions; China

\section{Introduction}

Fear of crime, an important social issue, affects daily activities [1,2] and mental/physical health of individuals [3,4]. Numerous studies have been written on this subject in Western countries such as the United States, the United Kingdom, and other European nations [5-9]. In line with increasing attention in cross-cultural studies in the field of fear of crime [10], recent literature on this construct has examined in non-Western contexts such as Turkey [11], Korea [12], Mexico [13], and China [14]. However, the amount of research on fear of crime in non-Western countries is still limited. It is useful to examine the correlates of fear of crime in these contexts as some correlates may vary across nations.

China has experienced a significant and continuous rise in overall victimization rates since the economic reform in 1982 [15-17], although the trend of violent crime is fluctuating. Meanwhile, people's worry about suffering crime has increased, and fear of crime has drawn increasing attention by authorities and scholars in China. Empirical fear of crime research in the Chinese context has verified the main claims of the theoretical approaches established in the West including the 
vulnerability model, disorder model, and victimization model [14,18-20]. However, only a few studies have examined the impact of culture-specific factors on fear of crime in China [18], so more studies in this area are desired.

Hukou, officially defined as a legal document recording the basic household population information, regulating population distribution and migration in China [21]. A person who chooses to move to a city without a hukou issued by the local government can work legally but lacks equal rights on public services, education, and healthcare compared to local hukou residents. Before the acceleration of China's economic reform in 1990s, the inequality of hukou was mainly reflected in the welfare of urban hukou and rural hukou, because the development gap between cities was small, and the gap between urban and rural areas was large. After the acceleration of economic reform, the eastern coastal areas have developed rapidly, the development gap between cities has rapidly expanded. A large number of internal migrants move to large cities to work, not only from rural areas to large cities but also from small cities to large cities. Nowadays, the inequality of hukou is largely reflected in the welfare between the local hukou and the non-local-hukou. Taking Guangzhou as an example, if a child was born in Guangzhou, the child cannot obtain the Guangzhou hukou (local hukou) if none of their parents have Guangzhou hukou. For residents from other cities or rural areas, the requirements for obtaining Guangzhou hukou are the same. In this study, we focus on the difference between non-local-hukou and local-hukou people.

As a classic model to explain the fear of crime, the vulnerability thesis assumes that objective or perceived personal vulnerability to crime, owing to physical and social reasons, promotes fear [6]. Physically vulnerable groups, such as women and the elder, tend to exhibit higher fear emotions [22], while less educated and unmarried residents are likely to have higher fear feelings because of their socially vulnerable characteristics [23]. Drawing on the concept of vulnerability, the present study attempts to incorporate a culture-specific indicator- $h u k o u-i n t o$ the vulnerability model to explain the fear of crime in China. Hence, hukou may be an indicator of social vulnerability for individuals in Chinese society.

This study contributes to the international literature on the fear of crime through an analysis of the relationship between hukou, perceived neighborhood conditions, and fear of crime in China. Internal migrant workers in cities generally are socially and economically vulnerable, and some of them live in poorer areas with no facilities and a high turnover of residents. Poor areas often lack neighborhood power (i.e., social support, social networks, and social control), which may lead to differences in neighborhood perception between local-hukou and non-local-hukou citizens. Further, previous studies indicated that vulnerable people restrict their daily activities to a lower risk range $[24,25]$. Non-local hukou holders may be more afraid of the unfamiliar environment, resulting in less contact with neighbors and unfamiliarity with the neighborhood environment. Guided by these existing theoretical concepts, the present study explores the possible relationship between hukou status and people's fear of crime.

\subsection{Hukou as an Indicator of Socioeconomic Vulnerability}

The hukou system has evolved with the times. To cope with the problems such as social instability and food shortages caused by the influx of farmers into the cities, the Chinese government established a comprehensive hukou system that has strict limits on citizens changing their permanent place of residence in the 1950s [21]. If a person was born in a rural hukou, it was difficult to obtain an urban hukou. In this way, the hukou system institutionalized inequality and strengthened the government's management and control over the population [26]. Since the 1990s, China's economic reform accelerated, resulting in increased population movement between urban and rural areas, allowing rural or non-local hukou people to work and live freely in cities. Currently, hukou policies tend to be more lenient in small cities than in large cities [27]. People can get the local hukou as long as they fulfill certain criteria in many small cities, while it is still difficult to get the local hukou in the big cities where the labor market is very competitive. For instance, local governments in large Chinese cities such as Beijing and 
Shanghai are tightening instead of loosening their admission threshold for the hukou [28]. Although the hukou system has undergone great reforms, currently, the unequal characteristics of hukou are still obvious. The hukou system divides the population into rural and urban, local hukou and non-local hukou, resulting in different benefits and possible discrimination between groups [29-31]. The benefits related to local hukou include subsidized education systems, welfare programs such as healthcare and pension, and other benefits. Non-local hukou holders do not have these benefits. Although non-local hukou holders can now attend schools in cities, the tuition fees they pay are much higher than those of local hukou residents. Some local governments require state-owned enterprises to only hire or give priority to local hukou residents.

This characteristic is in sharp contrast with Western countries, where citizens from different regions enjoy equal rights. Although the status of immigrants in Western societies is somewhat similar to that of non-local-hukou holders in Chinese cities (e.g., they are both related to lower levels of education and personal income, living in the disorderly neighborhoods) [32], hukou is still a unique feature in China. Immigrants in the West share equal opportunities in social welfare such as healthcare, pensions, public housing, and education, while non-local-hukou people lack equal opportunities to receive these benefits. Although no consensus has been reached, it is generally agreed that hukou serves as a significant form of institutionalized social capital inequalities in contemporary Chinese society [33]. It thus seems reasonable to propose that hukou represents a key social resource that might indicate social and economic vulnerability, and might be related to the fear of being a victim.

Under such an institutional environment, local-hukou-holders' neighborhood perceptions might differ from those of non-local-hukou people. Prior research has illustrated that the individual characteristics of non-local-hukou persons, such as education levels, economic status, and awareness of participation are associated with lower levels of community participation [34]. Moreover, non-local-hukou people also more likely to experience segregation [35] and social exclusion in their place of living [36]. For instance, non-local-hukou people often live in poor and crowded neighborhoods associated with security and social problems $[37,38]$. Their social networks are mainly rooted in their hometown rather than their living cities. Logically, the non-local-hukou population are generally socio-economic vulnerable groups, and living in areas with high levels of concentrated disadvantage, resulting in weak community participation. Meanwhile, the less familiar people are with an area, the more they rely on "reading" the physical and social cues around, so non-local-hukou people might care more about the community environment since most of them have a shorter length of residence than local-hukou residents. In this case, hukou status may be related to a series of models of the fear of crime, such as the victimization model, disorder model, and neighborhood concern model.

\subsection{Correlates of Fear of Crime}

Generally, fear of crime is conceptualized as an individual response to the perceived probability of being a victim of crime. Several theoretical insights have been offered to explain the fear of crime. Based on the framework of Hale [39], we review the correlates of fear of crime from a series of models.

According to the vulnerability model, women are likely to be more fearful than men [22], because women feel greater physical vulnerability, despite a lower objective risk of victimization. The inconsistency between perceived fear and objective risk for women may be because women have a greater risk of some serious victimization types such as domestic violence, rape, and sexual assault [40]. Old people also show higher levels of fear than the young $[23,41]$. This is also the result of physical vulnerability, that is, older people are unable to protect themselves in certain situations, such as walking alone after dark. Vulnerability is not simply physical, but also social. Income and race also affect fear of crime. People with less income might have a higher fear of crime [42,43]. The poor tend to live in areas with high crime rates, their property is vulnerable, and low incomes force them to rely more on public transportations that might put them in danger, thus promoting the fear of crime. Non-local-hukou residents are similar to immigrants. They leave the familiar living conditions and social support network and must adapt to the unfamiliar physical and social environment [44]. Although no research 
has directly analyzed the effect of one's hukou status on fear of crime, the empirical literature on immigrants reveals that fear of crime is high among immigrant populations [32,45]. Moreover, not all studies support the vulnerability model. For instance, some reported that younger people were more likely to be fearful of being victimized than older people $[11,20]$. Some did not find evidence that income is associated with fear of crime among individuals [46].

The vulnerability model is complementary to the victimization model. The victimization model is theorized that prior victimization, especially perceived severity of victimization [47], makes individuals more sensitive to crime and produces higher levels of fear and risk. This finding has been illustrated both in Western literature [48,49] and non-Western literature [12,21,47]. Moreover, indirect victimization leads to high fear of crime levels [50,51]. Empirical evidence suggests that fear of crime is related to some secondary informational sources about others who have been victimized, such as informal social networks and the media [52,53]. Instead, others revealed that the association between victimization and fear of crime may be weak $[5,54]$. This weak relationship may be due to the alleviation of the victim's emotions, the decline of memory, the prevention of criminal incidents, and the rationalization of crime incidents [5].

Fear of crime is caused by not merely the individual but the ecological characteristics, including perceived and objective conditions [55-58]. The disorder model, mainly composed of the Broken Windows theory, is widely used to explain fear of crime. Broken Windows theory posits that once the cues of the social and physical disorder occur frequently in the neighborhood, residents could believe that fewer neighbors care about community life, thereby triggering several neighborhood processes that contribute to the further disorder, criminal activities, and neighborhood decline, which could lead residents to exhibit higher levels of mistrust and feelings of fear $[59,60]$. A significant relationship was found between neighborhood disorder and fear of crime in a good number of Western studies [61-63] and non-Western literature [11,18]. Further, it was found that some factors, such as victimization experience [64] and neighborhood ties [65], moderated the effects of neighborhood disorder on the fear. Official Crime rates may function as an objective indicator of victimization risk and neighborhood disorder/disadvantage [66]. The higher crime rates in an area, the higher the actual risk of victimization. But many cases of crime are not directly visible to the public. Even if lots of research provided evidence that the crime rate leads to a higher fear of crime [67], some did not find such a relationship [7]. Another indicator of neighborhood disadvantage is that neighborhood income level is also associated with fear of crime [7].

Strongly correlated to the disorder model, collective efficacy posits that a neighborhood with a high level of collective efficacy may reduce social disorganization. Collective efficacy combines informal social integration and informal social control. Social integration is defined as a person's sense of belonging to their local neighborhood as well as their attachment to the neighborhood [68]. A neighborhood with high levels of trust and cohesion strengthens the residents' expectations that neighborhood social networks and ties can act as inhibitors of criminal activities. Consequently, residents who are familiar with their neighbors may experience lower levels of fear. While empirical research examining social integration has led to inconsistent findings [65], the majority suggests an inhibiting effect of social integration on fear of crime levels [6,69]. Informal social control, as a result of the neighborhood social integration [70], refers to the maintenance of social order to achieve common community values, such as living in a safe and orderly environment [71]. If individuals establish positive social networks with their neighbors, they tend to take interventions to prevent or stop violations in the neighborhood. Previous literature [72] has revealed the relationship between informal social control and decreased fear of crime.

Lastly, the neighborhood policing model claims that public perceptions of policing are related to people's feelings of fear $[7,73,74]$. Neighborhood policing improves the levels of police presence among the citizens, strengthens the actual connections between police and citizens, often leads citizens to have higher satisfaction with the police, and alleviates their fear of crime. In non-Western contexts, similar findings have been verified [75]. 


\subsection{The Present Study}

In light of the fact that existing research does not directly examine the effect of $h u k o u$ status on fear of crime, the current study attempts to test the possible relationship between hukou status and fear of crime based on the vulnerability model. As residents' perceptions of the neighborhood conditions might change from hukou status, thus, exploring how the effect of neighborhood conditions on fear of crime varies by hukou status is also an important theoretical issue.

Based on survey data collected from residents in the city of Guangzhou, this study answers two questions. First, we examine whether hukou status is associated with the fear of crime. Second, we examine if the influence of perceived neighborhood conditions on fear of crime varies by hukou status. It is expected that findings can provide a knowledge base for policymakers and police departments to develop relevant policies and practices to reduce fear of crime and improve people's quality of life in China.

\section{Data and Methodology}

\subsection{Data}

Our research was conducted in Guangzhou, located in the south of China, which is the third-largest city in China, with an urbanization rate of $85.53 \%$ (http://tjj.gz.gov.cn/tigb/glpcgb/content/post_2788684. $\mathrm{html}$ ). Urbanization rate means the share of urban population in the total population of the Guangzhou. If rural or urban migrants (without local hukou) live in the urban areas in Guangzhou for more than half a year, they are urban population. Guangzhou is the capital of Guangdong province, which has the highest net migrant inflow among all of China's provinces. As one of the most popular destinations for migrants in China, Guangzhou is an important center of China's manufacturing industry. In 2015, migrants working and living in Guangzhou were more than half of the city's total population [76].

The data for the current study were derived from a research survey (Project on Public Safety in Guangzhou Neighborhoods (PPSGN)) from January 2016 to April 2016 in Guangzhou. The survey was designed to gather 2000 responses based on the cost and representativeness of sampling. The sampling method was as follows. First, using principal component analysis (PCA) to extract the key characteristics of variables in Guangzhou 2010 Census data (more than 30 attributes) and then using clustering analysis to recognize the social areas. After that, all Guangzhou neighborhoods (census neighborhood is the smallest administrative division unit under the current statistical scale in China, which is derived from the 2010 National Census) were divided into nine types of social areas, e.g., local aging communities, middle-class areas in the old town, the university areas, etc (Urban social area refers to the aggregation of homogeneous population who live in a certain area, having roughly the same living standard, lifestyle, and living status. People living in different social areas have different characteristics, concepts, and behaviors. Reflected spatially, social areas are homogeneous urban areas composed of several communities. As early as in the 1950s, taking San Francisco as an example, some scholars began to study social areas [77].). The purpose of dividing the social areas was to carry out stratified sampling, thus the sample can represent various types of neighborhoods in Guangzhou. Second, the sample size of each social area was determined by the proportion of the population in each social area to the total population of Guangzhou. Third, diverse sampled neighborhoods were systematically selected using an equal probability of selection method. In the current survey, 90 sampled neighborhoods were selected. In this way, although the sample size was not large, it fully reflected different types of population in Guangzhou. Sampled neighborhoods are in Figure 1 (Zengcheng and Conghua districts were not included in the survey because of cost limitation, details in Figure 1). 


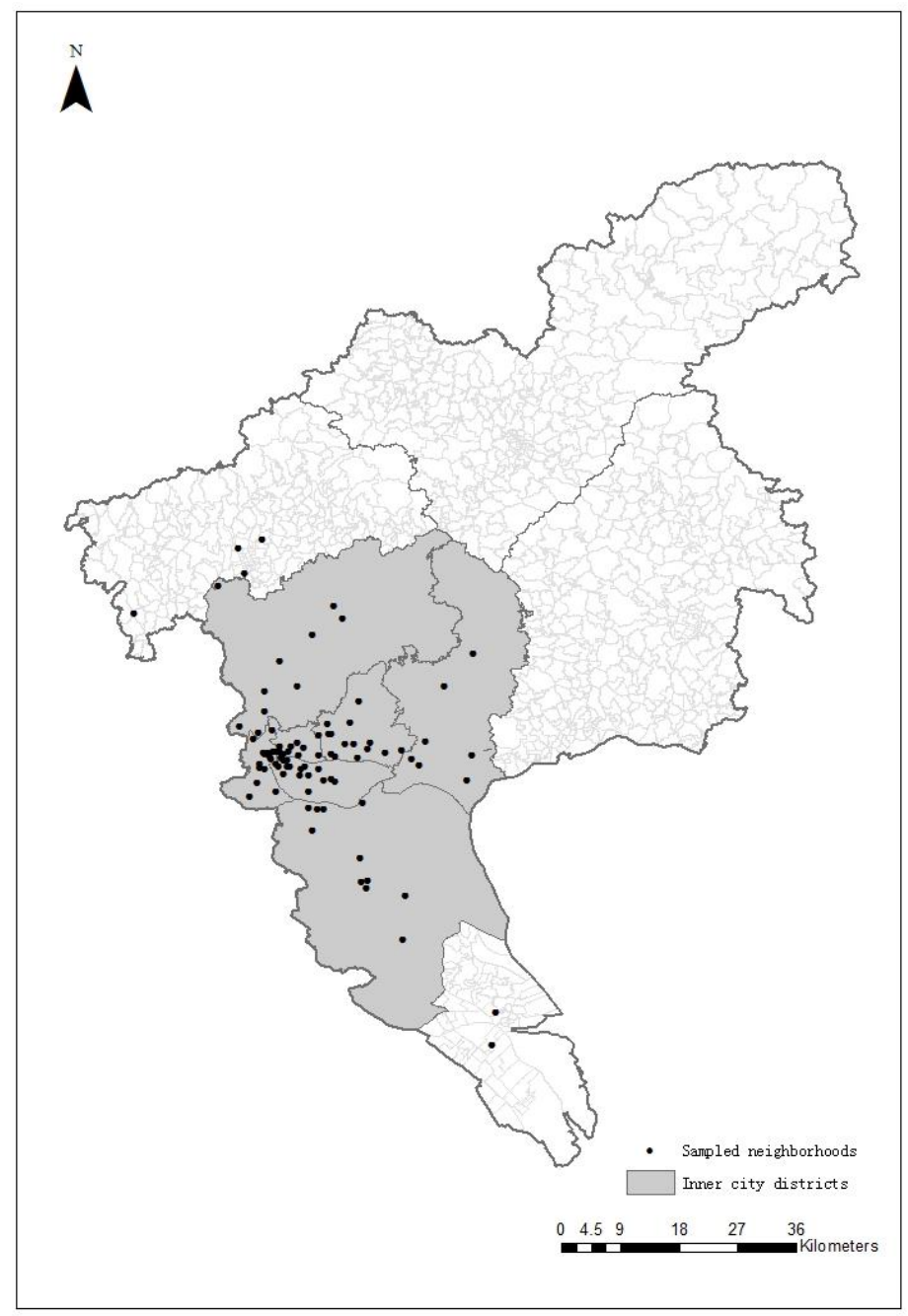

Figure 1. Location of sampled neighborhoods.

The questionnaire was distributed by the HOUSONWELL market research (http://www.hswell. $\mathrm{com} /$ ), a professional and well-known market research company in China. All surveyors were professionally trained to ensure the quality of the questionnaires. The questionnaire was presented on the tablet computer, and surveyors assisted participants to complete the survey. In addition to confirming the willingness of respondents to participate, it also needed to confirm whether the interviewees matched the requirements of the survey (college students and people under the age of 18 were declined to participate in the survey), so only eligible adults in each household included in the survey). The survey obtained sufficient samples in each neighborhood by the designed quota. The response rate was $87.4 \%$ higher than those of Western research. This is not surprising, as high response rates are typical in China [20]. Valid samples were collected (1994 in total), with a 95.1\% effective rate after excluding errors and missed answers in the conducted questionnaires. Then, we excluded those respondents who lived in the neighborhood for less than half a year, leaving in 1727 samples.

The sample consisted of 1727 respondents who were 19 to 89 years old, with $48.5 \%$ females and an average age of 39.05 years $(S D=14.25)$. These demographic indicators are consistent with the relevant composition in the 6th National Census; $49.6 \%$ of respondents were residents of non-Guangzhou hukou, which is consistent with the proportion in previous research in Guangzhou [76], and the proportion in the only official migrant population report by the General Affairs Office of Guangzhou Municipal People's Government (http://www.gz.gov.cn/zwgk/zjgb/zfgzbg/content/post_5894347.html). Other characteristics of the respondents are listed in Tables 1 and 2. 
Table 1. Descriptive Statistics of Variables.

\begin{tabular}{|c|c|c|c|c|}
\hline \multicolumn{2}{|c|}{ Individual-Level Variables } & \multicolumn{3}{|c|}{$\%(N)$} \\
\hline & & Total Sample (1727) & Non-Local Hukou (856) & Local Hukou (871) \\
\hline Age & Mean & 39.05 & 35.01 & 43.03 \\
\hline \multirow[t]{2}{*}{ Gender } & Female & $48.5 \%(837)$ & $41.4 \%(354)$ & $55.5 \%(483)$ \\
\hline & Male & $51.5 \%(890)$ & $58.6 \%(502)$ & $44.5 \%(388)$ \\
\hline \multirow[t]{8}{*}{ Education } & None & $1.4 \%(24)$ & $1.3 \%(11)$ & $1.5 \%(13)$ \\
\hline & Primary school & $9.3 \%(161)$ & $10.2 \%(87)$ & $8.5 \%(74)$ \\
\hline & Middle school & $26.9 \%(464)$ & $34.3 \%(294)$ & $19.5 \%(170)$ \\
\hline & High school & $26.0 \%(449)$ & $21.5 \%(184)$ & $30.4 \%(265)$ \\
\hline & $\begin{array}{l}\text { Secondary } \\
\text { specialized school }\end{array}$ & $8.9 \%(153)$ & $9.7 \%(83)$ & $8.0 \%(70)$ \\
\hline & $\begin{array}{l}\text { Junior college } \\
\text { degree }\end{array}$ & $16.2 \%(280)$ & $13.1 \%(112)$ & $19.3 \%(168)$ \\
\hline & Bachelor's degree & $11.1 \%(191)$ & $9.9 \%(85)$ & $12.2 \%(106)$ \\
\hline & $\begin{array}{l}\text { Master's degree } \\
\text { and above }\end{array}$ & $0.3 \%(5)$ & $0 \%(0)$ & $0.6 \%(5)$ \\
\hline \multirow[t]{7}{*}{ Personal income } & $\begin{array}{l}\text { Less than } 1000 \\
\text { Yuan }\end{array}$ & $9.7 \%(166)$ & $11.1 \%(95)$ & $8.2 \%(71)$ \\
\hline & 1000-1999 Yuan & $9.1 \%(157)$ & $7.1 \%(61)$ & $11 \%(96)$ \\
\hline & 2000-2999 Yuan & $26.7 \%(456)$ & $23.5 \%(201)$ & $29.5 \%(255)$ \\
\hline & 3000-4999 Yuan & $34.5 \%(596)$ & $36.8 \%(315)$ & $32.7 \%(286)$ \\
\hline & 5000-7999 Yuan & $14.5 \%(251)$ & $15.2 \%(130)$ & $14 \%(121)$ \\
\hline & 8000-9999 Yuan & $2.4 \%(42)$ & $3.5 \%(30)$ & $1.4 \%(12)$ \\
\hline & $\begin{array}{l}\text { More than 10,000 } \\
\text { Yuan }\end{array}$ & $3.1 \%(54)$ & $2.8 \%(24)$ & $3.3 \%(30)$ \\
\hline \multirow{2}{*}{$\begin{array}{c}\text { Direct } \\
\text { victimization }\end{array}$} & Victims & $40.1 \%(692)$ & $39.0 \%(334)$ & $41.1 \%(358)$ \\
\hline & Non-victims & $59.9 \%(1035)$ & $61.0 \%(522)$ & $58.9 \%(513)$ \\
\hline \multirow[t]{2}{*}{$\begin{array}{c}\text { Indirect } \\
\text { victimization }\end{array}$} & Victims & $46.4 \%(856)$ & $47.9 \%(410)$ & $44.9 \%(391)$ \\
\hline & Non-victims & $53.6 \%(926)$ & $52.1 \%(446)$ & $55.1 \%(480)$ \\
\hline \multirow[t]{2}{*}{ Hukou } & Local hukou & $50.4 \%(871)$ & - & - \\
\hline & Non-local hukou & $49.6 \%(856)$ & - & - \\
\hline
\end{tabular}

Table 2. Mean (Standard Deviations) and $t$ Tests for Neighborhood Conditions and Fear of Crime.

\begin{tabular}{|c|c|c|c|c|c|c|c|}
\hline \multirow{2}{*}{ Neighborhood Conditions } & \multicolumn{2}{|c|}{ Total Sample } & \multicolumn{2}{|c|}{ Non-Local Hukou } & \multicolumn{2}{|c|}{ Local Hukou } & \multirow{2}{*}{$t$-Test } \\
\hline & Mean & SD & Mean & SD & Mean & SD & \\
\hline \multicolumn{8}{|l|}{ Perceived conditions } \\
\hline Physical disorder & 2.930 & 0.807 & 2.900 & 0.820 & 2.960 & 0.793 & -1.523 \\
\hline Social disorder & 2.070 & 0.811 & 2.099 & 0.815 & 2.036 & 0.807 & 1.610 \\
\hline Informal social integration & 3.442 & 0.792 & 3.341 & 0.802 & 3.542 & 0.770 & $-5.316^{* *}$ \\
\hline Informal social control & 3.027 & 0.778 & 2.959 & 0.772 & 3.093 & 0.780 & $-3.611 * *$ \\
\hline $\begin{array}{l}\text { Neighborhood policing } \\
\text { Structural conditions }\end{array}$ & 3.230 & 0.864 & 3.190 & 0.881 & 3.260 & 0.461 & -1.744 \\
\hline Neighborhood education level & 0.138 & 0.205 & 0.137 & 0.209 & 0.140 & 0.200 & -0.318 \\
\hline $\begin{array}{l}\text { Neighborhood robbery rate } \\
\text { Outcome }\end{array}$ & 139.59 & 339.86 & 162.05 & 359.64 & 117.51 & 317.90 & $2.729 * *$ \\
\hline Fear of (neighborhood) Crime & 0.217 & 0.412 & 0.229 & 0.420 & 0.204 & 0.404 & 1.212 \\
\hline
\end{tabular}

\subsection{Measures}

\subsubsection{Dependent Variable}

Fear of Crime. In line with prior studies, the dependent variable for this study was formed on a five-item index investigating respondents' frequency of worry about becoming the victim of specific crime scenarios: a. my home might be broken into; b. my money or my property might be stolen in another way, like pick-pocketing; c. I might be beaten or hurt when I walk alone at night in the neighborhood; d. I might be robbed; e. I might be harassed. The question "How much do you worry 
about each of the following situations?" was put to respondents (5-point scale, 1 = totally not worried; $5=$ totally worried). Each person's fear was calculated using an average of the five items. The reliability of the measurement showed very strong internal consistency $(\alpha=0.91)$. To meet the requirement of the statistical model, the fear of crime was dichotomized. As 3-point means "medium", scores ranging from 1 to 3 (including 3) were coded to 0 (not worried), and scores ranging from 3 to 5 were coded to 1 (worried).

\subsubsection{Correlates of the Fear of Crime}

- Vulnerability variables

Physical vulnerability. Gender (dummy variable. Female $=1 ;$ male $=0$ ) and age (continuous variable) were included as indicators of physical vulnerability.

Social vulnerability. Hukou was measured by an individual-level variable in our survey, designed as a dummy variable; 0 stands for local hukou, and 1 stands for non-local hukou. Non-local hukou includes rural and urban migrants to Guangzhou but did not have local hukou status when the survey was conducted. Personal income (ordinal variable, from 1 to 7) provided a measure of the wealth of each respondent. Additionally, an education level (ordinal variable, from 1 to 8) was included in the list of individual-level variables.

- Victimization variables

Consistent with previous studies of victimization, two types of criminal victimization with a time-limited period were assessed: direct victimization and indirect victimization. Direct victimization was indicated by whether the respondent experienced a crime type within the three years preceding the survey ( 1 for victimized, and 0 for non-victimized). Indirect victimization was indicated by whether the respondent heard about a crime event reported by households in neighboring dwellings within the three years preceding the survey ( 1 for victimized, and 0 for non-victimized).

- Perceived neighborhood conditions

Perceived physical disorder. Neighborhood disorder is a crucial predictor of the fear of crime. Perceived physical disorder contains four items, calculated by the mean value, regarding how serious a problem is in the following activities in the respondents' neighborhoods: (1) damaged public facilities; (2) mess garbage and cars; (3) graffiti and disordered advertisements; (4) and noisy neighborhood environment. The response categories range from $1=$ not at all serious to $5=$ very serious $(\alpha=0.90$; $M=2.930, S D=0.807)$.

Perceived social disorder. Correspondingly, the perceived social disorder also contains four items, calculated by the mean value. It was measured by the following question: "how serious are the following activities within the neighborhood: (1) teenagers gather in the streets to hang around; (2) neighbors are prone to conflict; (3) suspicious strangers are in the neighborhood; (4) and drunken persons are in the neighborhood at night." The response categories range from $1=$ not at all serious to $5=$ very serious $(\alpha=0.83 ; M=2.070, S D=0.811)$.

Perceived informal social integration. Informal social integration indicates collective effectiveness in the community and is related to the decreased fear of crime in general. It contains four items, measured by the following question: "how often do the following phenomenon occur in the neighborhood: (1) neighbors greet each other; (2) neighbors visit each other; (3) neighbors borrow items from each other; (4) and neighbors are in harmony with each other'. Higher value represents more harmonious informal social integration perception $(\alpha=0.84 ; M=3.442, S D=0.792)$.

Perceived informal social control. Following prior literature, our study included the following questions: (1) If kids were drawing graffiti in your neighborhood would it be likely that the residents of the neighborhood would try to do something about it? (2) If there was a fight outside your residence and someone was beaten up, is it likely that any of your neighbors would intervene to stop it? (3) If a stranger was hanging around in your neighborhood, is it likely that any of your neighbors would do something about it? (4) If kids in your neighborhood were skipped school would it be likely that the residents of the neighborhood would inquiry and let their parents know? Informal social control 
was measured by aggregating the responses to the four questions. The resulting scale ranged from 1 (lower informal social control) to 5 (higher informal social control) and demonstrated acceptable internal consistency $(\alpha=0.82, M=3.027, S D=0.778)$.

Perceived neighborhood policing. Neighborhood policing was presumed to reversely relate to fear of crime. Although generally perceived neighborhood policing was measured in various dimensions, our study used a single item to measure it due to questionnaire limitations. The question was: how often do you see police officers or security patrols in and around your neighborhood? The higher value, the higher perception of neighborhood policing $(M=3.23, S D=0.864)$.

- Neighborhood structural conditions

As some non-Guangzhou-hukou citizens may live in disadvantaged neighborhoods, the present study controls two neighborhood disadvantage indicators to avoid the results becoming spurious. Although neighborhood income level is an ideal factor predicting neighborhood disadvantage, there is no accessible neighborhood-level income data in Guangzhou. Neighborhood-level education was used as an alternative indicator, which was highly related to income, reflecting the neighborhood disadvantage. Then, in line with previous literature, we obtained the robbery rate as another indicator of the neighborhood disadvantage.

Neighborhood education level. Neighborhood education level was calculated as the ratio between the number of people with bachelor's degrees or higher and the number of inhabitants in each census neighborhood (from 2010 National Census) $(M=0.138, S D=0.205)$. A higher neighborhood education level refers to a lower level of neighborhood disadvantage.

Robbery rate. Robbery rate (per 100,000 population) was calculated for each of the 90 census neighborhoods in the sample by averaging official police counts of robbery for 2014 and 2015, dividing by the census neighborhood population, and multiplying by 100,000. Robbery crime data obtained from Guangzhou Public Security Bureau $(M=139.59, S D=339.86)$.

\subsection{Analytic Strategy}

An ideal approach is to use a multilevel model, since the variance in the neighborhood level can be considered. In this study, each neighborhood has only approximately 20 samples. It might not fully represent the neighborhood-level perceptions. We conducted a preliminary analysis from a multilevel perspective. The unconditional intra-class coefficient (ICC) for our outcome, fear of crime, was 0.103. This means that only $10.3 \%$ of the variance in fear was between neighborhoods. It also demonstrates that the multilevel model may not be perfect for our research, although the original dependent variable was continuous, with skewness and kurotosis values under one (Skewness $=0.293$, Kurtosis $=-0.471$ ), it did not pass the Kolmogorov-Smirnov(KS)-test $(p<0.05)$, and the OLS regression approach is not most appropriate. According to previous studies [22,46], the present study uses a binary logistic regression model. Using the dichotomous fear of crime as the dependent variable, a binary logistic regression model was employed to test the influence of hukou and perceived neighborhood conditions on the fear of crime, with controlling relevant factors.

First, we perform a series of independent sample $t$ tests to compare neighborhood perceptions and fear of crime between local-hukou and non-local-hukou people. Second, we conduct a bivariate correlation analysis to examine the correlations between variables. Third, binary logistic regression models are used to examine the effects of hukou on fear of crime and to test whether the relationship between neighborhood conditions and fear of crime varies by hukou. All analyses were performed using SPSS 22.0 software (IBM SPSS, Armonk, NY, USA).

\section{Results}

\subsection{Descriptive Statistics and Correlations for the Variables}

The descriptive demographic information is displayed in Tables 1 and 2. More respondents were identified as men and non-victims. Most respondents reported low levels of fear of crime $(\mathrm{M}=0.217$; 
1353 samples are not worried and 374 samples are worried). There are some differences in neighborhood condition perceptions between non-local and local hukou respondents (Table 2). Non-local hukou holders indicated higher levels of social disorder $(\mathrm{M}=2.099)$ compared to local hukou holders $(\mathrm{M}=2.036)$, while local hukou persons had higher physical disorder perception ( $\mathrm{M}=2.960)$ than non-local hukou persons $(\mathrm{M}=2.900)$. Moreover, local hukou holders exhibited higher levels of informal social integration, informal social control, and neighborhood policing. Independent sample $t$ tests revealed statistically significant differences in social integration and social control between the local hukou and non-local hukou holders, but no differences in physical and social disorder, and neighborhood policing.

Bivariate correlations were detected using Spearman's correlation coefficient (Appendix A). Whilst many significant correlations were occurring, none were bigger than 0.50 , and there was no concern for multicollinearity in the subsequent tests.

\subsection{Examining the Relationship between Hukou and the Fear of Crime}

The analysis steps are as follows. First, a binary logistic regression model including individual-level variables was estimated. Further, an integrated model was estimated, where the model includes individual-level measures and ecological variables simultaneously. The results can be found in Table 3 .

Table 3. Binary Logistic Regression Models for Fear of Crime.

\begin{tabular}{|c|c|c|c|c|c|c|}
\hline \multirow{3}{*}{ Independent Variables } & \multicolumn{6}{|c|}{ Fear of Crime } \\
\hline & \multicolumn{3}{|c|}{ Model 1} & \multicolumn{3}{|c|}{ Model 2} \\
\hline & B & SE & $\operatorname{Exp}(B)$ & B & SE & $\operatorname{Exp}(B)$ \\
\hline \multicolumn{7}{|l|}{ Neighborhood conditions } \\
\hline Physical disorder & & & & $0.391^{* *}$ & 0.087 & 1.478 \\
\hline Social disorder & & & & $0.347^{* *}$ & 0.082 & 1.415 \\
\hline Informal social integration & & & & -0.076 & 0.085 & 0.926 \\
\hline Informal social control & & & & -0.049 & 0.089 & 0.952 \\
\hline Neighborhood policing & & & & $-0.184 *$ & 0.072 & 0.832 \\
\hline \multicolumn{7}{|l|}{ Structural conditions } \\
\hline Neighborhood education level & & & & $-0.956 * *$ & 0.353 & 0.384 \\
\hline \multicolumn{7}{|l|}{ Individual characteristics } \\
\hline Age & -0.006 & 0.005 & 0.994 & -0.003 & 0.005 & 0.997 \\
\hline Gender & $0.512 * *$ & 0.125 & 1.668 & $0.564^{* *}$ & 0.129 & 1.757 \\
\hline Education & -0.081 & 0.048 & 0.922 & -0.056 & 0.049 & 0.946 \\
\hline Personal income & -0.012 & 0.049 & 0.988 & 0.011 & 0.051 & 1.011 \\
\hline Direct victimization & $0.583^{* *}$ & 0.144 & 1.792 & $0.480^{* *}$ & 0.150 & 1.616 \\
\hline Indirect victimization & $0.400 * *$ & 0.146 & 1.492 & 0.207 & 0.152 & 1.230 \\
\hline Hukou status & 0.173 & 0.132 & 1.888 & 0.135 & 0.136 & 1.445 \\
\hline Constant & $-1.340^{* *}$ & 0.400 & 0.262 & $-2.814^{* *}$ & 0.595 & 0.060 \\
\hline \multicolumn{7}{|l|}{ Model diagnostics } \\
\hline$x^{2}$ & \multicolumn{3}{|c|}{$75.930(p<0.00)$} & \multicolumn{3}{|c|}{$150.202(p<0.00)$} \\
\hline-2 log likelihood & \multicolumn{3}{|c|}{1712.70} & \multicolumn{3}{|l|}{1638.43} \\
\hline Nagelkerke $\mathrm{R}^{2}$ & 0.067 & & & 0.129 & & \\
\hline
\end{tabular}

Note. ${ }^{* *} p<0.01 ; * p<0.05$

The Model 1 fits the data $\left(\chi^{2}=75.930, p<0.00\right)$. Gender, direct, and indirect victimization experience were statistically significant and related to fear in the expected direction $(\mathrm{B}=0.512, p<0.01$, $\operatorname{Exp}(B)=1.668 ;$ and $B=0.583, p<0.01, \operatorname{Exp}(B)=1.792 ;$ and $B=0.400, p<0.01, \operatorname{Exp}(B)=1.492$; respectively). Hukou has no statistically significant effect on the fear of crime $(p>0.05)$. The remaining characteristics were not found to be significant predictors of fear of crime.

Model 2 demonstrated the effects of individual characteristics and neighborhood perceptions on fear of crime. Again, there was no significant direct relationship between hukou and fear of crime 
$(p>0.05)$ after controlling neighborhood conditions. Besides, physical and social disorder exerted a positive effect on fear of crime $(B=0.391, p<0.01, \operatorname{Exp}(B)=1.478$; and $B=0.347, p<0.01, \operatorname{Exp}(B)=1.415$; respectively). Perceived neighborhood policing was significantly oppositely related to fear of crime $(B=-0.184, p<0.05, \operatorname{Exp}(B)=0.832)$. Informal social integration and control, however, were not statistically associated with fear of crime. Overall, the Model 2 also fits the data well $\left(\chi^{2}=150.202\right.$, $p<0.00)$.

\subsection{Examining the Effects of Perceived Neighborhood Conditions on Fear of Crime by Hukou Status}

To further detect whether the effects of perceived neighborhood conditions on fear of crime are different between the local-hukou and non-local-hukou people, this study conducted two models for the two groups, respectively. A coefficient comparison test [78] was employed to observe what variables have similar effects and which ones have significant effects in one group, but not in the other (Table 4).

Table 4. Binary Logistic Regression Results of Fear of Crime by hukou status.

\begin{tabular}{|c|c|c|c|c|c|c|c|}
\hline \multirow{3}{*}{ Independent Variables } & \multicolumn{7}{|c|}{ Fear of Crime } \\
\hline & \multicolumn{3}{|c|}{ Non-Local Hukou } & \multicolumn{3}{|c|}{ Local Hukou } & \multirow{2}{*}{$\begin{array}{c}\text { Comparison } \\
\text { Z score }\end{array}$} \\
\hline & B & SE & $\operatorname{Exp}(B)$ & B & SE & $\operatorname{Exp}(B)$ & \\
\hline \multicolumn{8}{|l|}{ Neighborhood conditions } \\
\hline Physical disorder & $0.365 * *$ & 0.122 & 1.441 & $0.434^{* *}$ & 0.123 & 1.543 & -0.39 \\
\hline Social disorder & $0.341^{* *}$ & 0.048 & 1.406 & $0.105^{*}$ & 0.060 & 1.110 & $3.07 * *$ \\
\hline Informal social integration & 0.027 & 0.047 & 1.027 & $-0.144^{* *}$ & 0.054 & 0.865 & $2.39 *$ \\
\hline Informal social control & -0.158 & 0.134 & 0.853 & 0.016 & 0.120 & 1.016 & -0.97 \\
\hline $\begin{array}{l}\text { Neighborhood policing } \\
\text { Structural conditions }\end{array}$ & $-0.234^{*}$ & 0.107 & 0.791 & -0.138 & 0.101 & 0.871 & -0.66 \\
\hline Neighborhood education level & $-1.181 *$ & 0.514 & 0.307 & -0.706 & 0.491 & 0.494 & -0.67 \\
\hline $\begin{array}{l}\text { Neighborhood robbery rate } \\
\text { Individual characteristics }\end{array}$ & 0.000 & 0.000 & 1.000 & 0.000 & 0.000 & 1.000 & 0.59 \\
\hline Age & -0.003 & 0.009 & 0.997 & -0.006 & 0.007 & 0.994 & 0.32 \\
\hline Gender & $0.610 *$ & 0.190 & 1.840 & $0.495^{* *}$ & 0.179 & 1.640 & 0.44 \\
\hline Education & 0.027 & 0.067 & 1.027 & $-0.153 *$ & 0.073 & 0.858 & 1.82 \\
\hline Personal income & 0.014 & 0.070 & 1.014 & 0.023 & 0.075 & 1.023 & -0.08 \\
\hline Direct victimization & $0.405^{*}$ & 0.213 & 1.499 & $0.561^{* *}$ & 0.216 & 1.753 & -0.52 \\
\hline Indirect victimization & $0.375^{*}$ & 0.218 & 1.455 & 0.069 & 0.219 & 1.071 & 0.99 \\
\hline Constant & $-3.567 * *$ & 0.792 & 0.028 & $-1.950 *$ & 0.840 & 0.142 & \\
\hline \multicolumn{8}{|l|}{ Model diagnostics } \\
\hline$x^{2}$ & \multicolumn{3}{|c|}{$89.725(p<0.00)$} & \multicolumn{3}{|c|}{$70.042(p<0.00)$} & \\
\hline$-2 \log$ likelihood & \multicolumn{3}{|c|}{763.725} & \multicolumn{3}{|c|}{863.549} & \\
\hline Nagelkerke $\mathrm{R}^{2}$ & \multicolumn{3}{|l|}{0.157} & \multicolumn{3}{|l|}{0.118} & \\
\hline
\end{tabular}

The model estimates for non-local-hukou people, physical disorder, social disorder, and neighborhood policing exhibited the expected direction and significance. Among local-hukou people, the effect of physical disorder, social disorder, and social integration was significant. The effect of social control was not significant in either category.

When examing the outcome of the tests for differences in regression coefficients by hukou status, the Z-score results indicate that while perceived social disorder is significantly increasing one's level of fear of crime, the effect of social disorder on fear of crime is significantly stronger for the non-local-hukou people than it is for their counterparts $(Z=3.07)$. Conversely, the effect of perceived social integration as a factor able to reduce fear of crime is significant for the local-hukou but not for the non-local-hukou $(Z=2.39$ ). The lack of significance corresponding to the $Z$ score for physical disorder indicates that physical disorder had a similar effect on fear of crime in both comparison groups. This applies to perceived social control and neighborhood policing, too. 


\section{Discussion}

When examining determinates of fear of crime in the non-Western context, it is better to consider the specific social and cultural characteristics. In rapidly urbanizing China, a large number of migrants come to live in the cities, while their rights are not equal because of lacking the local hukou. In this social background, hukou plays a role as an indicator of social vulnerability. Residents with and without hukou might have different levels of neighborhood participation and perception. This study examined whether hukou status is associated with fear of crime in China. Although the results indicate no statistically significant direct effect of hukou status on fear of crime, hukou status does significantly moderate the effects of perceived neighborhood conditions on fear of crime. That is, perceived neighborhood conditions' effects on fear are conditional on one's hukou status: non-local hukou, perception of the social disorder has more of the detrimental effect on fear, and perception of social integration has less of the helpful effect on fear. Our results suggest that loosening hukou restrictions in China's large cities would help improve people's safety perception in the living environment.

Our findings make a further understanding between hukou and fear of crime in China. Liu et al. [20] defined the rural migrant concentration variable measured by the proportion of respondents who report that temporary rural workers are living in their neighborhood, and their result indicated that the perception of more migrant workers living in the neighborhoods increases perceived disorder. Although there are some differences between the hukou in our study and rural migrant concentration in Liu et al. [20], the variables both reflect the internal migration situation in China, and both reveal that internal migration is associated with neighborhood disorder in the Chinese context. Furthermore, the findings of Liu et al. [20] did not demonstrate a statistically significant association between rural migrant concentration and fear of crime. Similarly, our result also did not show the significant effect of the hukou on fear of crime. As a socially vulnerable indicator, the hukou status only indirectly influences the fear of crime through the moderation of some neighborhood conditions.

Some perspectives may explain why hukou has no direct effect on fear of crime. On one hand, a small proportion of people who do not have a Guangzhou hukou may come from other developed cities and rural areas. Their socioeconomic level is not low, so they are less vulnerable and may have a lower fear of neighborhood crime. On the other hand, even if a person does not have a Guangzhou $h u k o u$ and comes from a poor area, the person may live with other migrants from the same hometown and have their social network [36]. In this way, the social network may weaken the harmful effect of non-Guangzhou hukou. The findings of this study show that some ecological correlates of fear of crime between the Guangzhou hukou and the non-Guangzhou hukou are different, which indicates the indirect effect of hukou on fear of crime via ecological factors.

Western studies on the possible effects of immigrants on people's feelings of safety have produced empirical findings. Prior literature suggests that ethnic minorities and immigrant populations are likely to exhibit higher levels of fear of crime than the majority [32,45]. In our study, to some extent, domestic migrants with non-local hukou are similar to minorities and immigrants in Western societies because they all must adapt to the unfamiliar physical and social environment. Additionally, although the present research is the first to study the interplay of the hukou and neighborhood conditions on fear of crime, previous Western studies have explored the interplay of race and neighborhood conditions. For instance, a study by Rountree and Land [79] in the Seattle sample examined the interaction effect analysis of neighborhood incivilities and race on risk perception, although no significant effects were found. Hence, in examining the topic of internal migration's fear of crime in China, we can draw on the theories and findings of Western literature about the fear of crime among minorities and immigrants.

Results for the theoretical ecological variables (perception of police, social, and physical disorder) were significantly associated with fear of crime. Consistent with prior literature [80], this would suggest that the role of environmental variables is vital. Levels of disorganization are higher in the large cities in China, such as Guangzhou. The gap of wealth is greater and the crime rate is higher in the large cities relative to other areas, because of the inequitable distribution of resources between the large cities and the rest of China. Within the rapid process of urbanization, urban villages (surrounded 
by skyscrapers and other modern urban buildings) have appeared in many Chinese cities. The high crime rate is one of the persistent stigmas of urban villages [81]. Furthermore, when the neighborhood policing factor is applied to the Guangzhou context, relatively high levels of police patrols could be considered. Due to the importance of social stability in China, armed police stand guard at major public spaces, and a variety of lower-level security guards are present, and surveillance cameras are visible in many corners of public spaces. The findings indicate that variables at the ecological level continue to be significant for fear of crime research, and further investigation into these variables in the comparison of Western and non-Western contexts is much desired.

Results from this study provide some directions for policymakers to alleviate fears of the public. It has been widely criticized that the hukou system has many flaws, such as the restriction of freedom of movement, the inequality of urban and rural residents' status, and the misallocation of labor resources [26]. Recently China is relaxing hukou restrictions in small and medium-sized cities to solve migrant workers' residency rights and promote urbanization. This study, based on a first-tier city in China, revealed the indirect association between hukou and perception of safety. It is suggested to further loosen the restrictions of the hukou system, especially in China's first-tier cities (Beijing, Shanghai, Guangzhou, and Shenzhen), where the hukou restrictions are still relatively strict. The authorities should also focus on improving the neighborhood environment where lots of non-local hukou residents live, and help them integrate into the community further (e.g., provide more social support, and organize various neighborhood activities).

The present research can be extended and improved in several aspects. First, the variable hukou status in the present study does not capture inter-group differences (e.g., rural migrants, urban migrants, and locally-born residents), which might cause the non-significant effect of hukou status on fear of crime. Second, the data we studied were cross-sectional. In fact, over a long period, individual characteristics and environmental conditions might change, potentially contributing to shifts in perception of neighborhood conditions and levels of fear [82]. With more waves of data, more complex patterns of association among hukou, perception of the environment, and fear would be examined. Lastly, because the sample size of each neighborhood is not large enough, we did not aggregate the indicators of perceived neighborhood conditions to the neighborhood level and did not control for between and within neighborhood differences. More sophisticated models might be used in the future. Despite these limitations, the model in the current study revealed useful findings on fear of crime in the Chinese context.

\section{Conclusions}

In summary, this study is in the group of studies interested in how the integrated model of fear of crime varies by the social and cultural contexts. Traditional correlates of fear of crime from Western theories have been verified in the Chinese context. Women, victimization experience, perceived physical and social disorder, and perceived neighborhood policing are associated with residents' fear of crime. More importantly, it revealed that a culture-specific indicator, hukou in the Chinese context, has no direct impact on the fear of crime, but the effect of perceived neighborhood conditions on fear of crime varies from hukou status. Hukou status influences individuals' neighborhood condition perceptions, then leading to the fear of crime variation. This study adds to the international literature by revealing the conditional effect of the hukou on fear in the Chinese context.

Author Contributions: F.J., L.L. and S.Z. conceived and designed the structure and case study of the paper; G.S. helped reorganize the structure of the paper; G.S., L.L., S.Z. and F.J. designed the questionnaire; F.J. analyzed the data and wrote the paper. All authors have read and agreed to the published version of the manuscript.

Funding: This research was funded by the Research Team Program of Natural Science Foundation of Guangdong Province, China (No. 2014A030312010), and the National Key R\&D Program of China (Nos. 2018YFB0505500, 2018YFB0505503), and the International Program for Ph.D. Candidates, Sun Yat-sen University, and the National Natural Science Foundation of China (Nos. 41531178, 41901177, 41901172), and the Key Scientific Research Program of Guangzhou (Nos. 201804020016). 
Acknowledgments: We want to thank Jon Bannister at the Manchester Metropolitan University for his constructive comments on an earlier version. We also special thank to an anonymous referee, whose valuable comments and suggestions helped us improve the paper greatly. Any errors that remain in the paper are the responsibility of the first author.

Conflicts of Interest: The authors declare no conflict of interest. 


\section{Appendix A}

Table A1. Bivariate Correlations of Variables.

\begin{tabular}{|c|c|c|c|c|c|c|c|c|c|c|c|c|c|c|c|c|}
\hline & & 1 & 2 & 3 & 4 & 5 & 6 & 7 & 8 & 9 & 10 & 11 & 12 & 13 & 14 & 15 \\
\hline 1 & Age & - & & & & & & & & & & & & & & \\
\hline 2 & Gender & $0.11^{* *}$ & - & & & & & & & & & & & & & \\
\hline 3 & Education & $-0.40 * *$ & $-0.07 *$ & - & & & & & & & & & & & & \\
\hline 4 & Personal income & $-0.20 * *$ & $-0.22 * *$ & $0.39 * *$ & - & & & & & & & & & & & \\
\hline 5 & Direct victimization & $-0.08 *$ & -0.02 & $0.07 *$ & 0.02 & - & & & & & & & & & & \\
\hline 6 & Indirect victimization & $-0.11 * *$ & 0.02 & $0.09 * *$ & 0.01 & $0.41^{* *}$ & - & & & & & & & & & \\
\hline 7 & Hukou & -0.26 ** & $-0.14 *$ & $-0.13^{* *}$ & -0.02 & 0.02 & -0.01 & - & & & & & & & & \\
\hline 8 & Physical disorder & 0.02 & -0.02 & -0.01 & -0.01 & $0.12 * *$ & $0.15^{* *}$ & 0.04 & - & & & & & & & \\
\hline 9 & Social disorder & $-0.14^{* *}$ & $-0.06 *$ & 0.03 & -0.01 & $0.30^{* *}$ & $0.30 * *$ & $-0.07 * *$ & $0.33 * *$ & - & & & & & & \\
\hline 10 & Informal social integration & $0.13^{* *}$ & $0.09 * *$ & -0.01 & -0.00 & $-0.07 *$ & $-0.06 *$ & $0.18^{* *}$ & $0.10 * *$ & $-0.10^{* *}$ & - & & & & & \\
\hline 11 & Informal social control & 0.05 & 0.03 & $0.05 *$ & 0.01 & -0.01 & -0.01 & $0.09^{* *}$ & $0.13 * *$ & 0.05 & $0.31^{* *}$ & - & & & & \\
\hline 12 & Neighborhood policing & $0.06^{*}$ & -0.02 & -0.01 & -0.00 & -0.04 & -0.04 & $0.06 *$ & -0.04 & $-0.07^{* *}$ & $0.16^{* *}$ & $0.18 * *$ & - & & & \\
\hline 13 & Neighborhood education level & -0.01 & $0.05 *$ & $0.22 *$ & $0.13 *$ & $-0.05 *$ & $-0.11^{* *}$ & $0.08^{* *}$ & $-0.06 * *$ & $-0.16^{* *}$ & -0.02 & $0.06^{* *}$ & 0.02 & - & & \\
\hline 14 & Neighborhood robbery rate & -0.04 & -0.01 & $-0.06^{*}$ & 0.00 & 0.02 & $0.08^{* *}$ & $-0.11 * *$ & 0.01 & $0.12 * *$ & $-0.06 * *$ & -0.03 & -0.02 & $-0.23 * *$ & - & \\
\hline 15 & Fear of Crime & 0.00 & $0.11^{* *}$ & -0.02 & $-0.05 *$ & $0.16 * *$ & $0.15^{* *}$ & 0.03 * & $0.19 * *$ & $0.16^{* *}$ & -0.03 & 0.02 & $-0.07^{* *}$ & -0.10 & 0.01 & - \\
\hline
\end{tabular}




\section{References}

1. Mesch, G.S. Perceptions of risk, lifestyle activities, and fear of crime. Deviant Behav. 2000, 21, 47-62. [CrossRef]

2. Stodolska, M.; Shinew, K.J.; Acevedo, J.C.; Roman, C.G. "I was born in the hood": Fear of crime, outdoor recreation and physical activity among Mexican-American urban adolescents. Leisure Sci. 2013, 35, 1-15. [CrossRef]

3. Lorenc, T.; Clayton, S.; Neary, D.; Whitehead, M.; Petticrew, M.; Thomson, H.; Cummins, S.; Sowden, A.; Renton, A. Crime, fear of crime, environment, and mental health and wellbeing: Mapping review of theories and causal pathways. Health Place 2012, 18, 757-765. [CrossRef]

4. Sulemana, I. The effect of fear of crime and crime victimization on subjective well-being in Africa. Soc. Indic. Res. 2015, 121, 849-872. [CrossRef]

5. Box, S.; Hale, C.; Andrews, G. Explaining fear of crime. Br. J. Criminol. 1988, 28, 340-356. [CrossRef]

6. Franklin, T.W.; Franklin, C.A.; Fearn, N.E. A multilevel analysis of the vulnerability, disorder, and social integration models of fear of crime. Soc. Justice Res. 2008, 21, 204-227. [CrossRef]

7. Scarborough, B.K.; Like-Haislip, T.Z.; Novak, K.J.; Lucas, W.L.; Alarid, L.F. Assessing the relationship between individual characteristics, neighborhood context, and fear of crime. J. Crim. Justice 2010, 38, 819-826. [CrossRef]

8. Jermsittiparsert, K.; Akahat, N. Fear of Crime among Students of Kalasin Rajabhat University. Res. J. Appl. Sci. 2016, 11, 54-61.

9. Maier, S.L.; DePrince, B.T. College students' fear of crime and perception of safety: The influence of personal and university prevention measures. J. Crim. Justice Educ. 2020, 31, 63-81. [CrossRef]

10. Addington, L.A.; Yablon, Y.B. A cross-national examination of fear in disadvantaged schools: US and Israeli-Arab student experiences. Vict. Offenders 2011, 6, 325-340. [CrossRef]

11. Karakus, O.; McGarrell, E.F.; Basibuyuk, O. Fear of crime among citizens of Turkey. J. Crim. Justice 2010, 38, 174-184. [CrossRef]

12. Lee, J.; Cho, S. The impact of crime rate, experience of crime, and fear of crime on residents' participation in association: Studying 25 districts in the City of Seoul, South Korea. Crime Prev. Commun. Saf. 2018, 20, 189-207. [CrossRef]

13. Villarreal, A.; Yu, W.H. Crime, fear, and mental health in Mexico. Criminology 2017, 55, 779-805. [CrossRef]

14. Song, G.; Liu, L.; He, S.; Cai, L.; Xu, C. Safety perceptions among African migrants in Guangzhou and Foshan, China. Cities 2020, 99, 102624. [CrossRef]

15. Bai, J. Crimes, Causes and Punishments in Contemporary China: A Statistical Analysis. Peking Univ. Law J. 2014, 2, 287-314.

16. Tang, Y.; Zhu, X.; Guo, W.; Ye, X.; Hu, T.; Fan, Y.; Zhang, F. Non-Homogeneous diffusion of residential crime in urban China. Sustainability 2017, 9, 934. [CrossRef]

17. Long, D.; Liu, L.; Feng, J.; Zhou, S.; Jing, F. Assessing the influence of prior on subsequent street robbery location choices: A case study in ZG city, China. Sustainability 2018, 10, 1818. [CrossRef]

18. Zhang, L.; Messner, S.F.; Liu, J.; Zhuo, Y.A. Guanxi and fear of crime in contemporary urban China. Br. J. Criminol. 2009, 49, 472-490. [CrossRef]

19. Yan, E.; Qin, N. Prevalence and psychosocial correlates of the fear of crime in older Chinese. J. Adult Prot. 2014, 16, 264-275.

20. Liu, J.; Messner, S.F.; Zhang, L.; Zhuo, Y. Socio-demographic correlates of fear of crime and the social context of contemporary urban China. Am. J. Commun. Psychol. 2009, 44, 93-108. [CrossRef]

21. Chan, K.W.; Zhang, L. The hukou system and rural-urban migration in China: Processes and changes. China Q. 1999, 160, 818-855. [CrossRef] [PubMed]

22. Yates, A.; Ceccato, V. Individual and spatial dimensions of women's fear of crime: A Scandinavian study case. Int. J. Comp. Appl. Crim. Justice 2020, 1-16. [CrossRef]

23. Greve, W.; Leipold, B.; Kappes, C. Fear of crime in old age: A sample case of resilience? J. Gerontol. Ser. B 2018, 73, 1224-1232. [CrossRef] [PubMed]

24. Whitley, R.; Prince, M. Fear of crime, mobility and mental health in inner-city London, UK. Soc. Sci. Med. 2005, 61, 1678-1688. [CrossRef]

25. Lehning, A.; Kim, K.; Smith, R.; Choi, M. Does economic vulnerability moderate the association between transportation mode and social activity restrictions in later life? Ageing Soc. 2018, 38, 2041-2060. [CrossRef] 
26. Liu, Z. Institution and inequality: The hukou system in China. J. Comp. Econ. 2005, 33, 133-157. [CrossRef]

27. Colas, M.; Ge, S. Transformations in China's internal labor migration and hukou system. J. Labor. Res. 2019, 40, 296-331. [CrossRef]

28. Zhang, J.; Wang, R.; Lu, C. A quantitative analysis of Hukou reform in Chinese cities: 2000-2016. Growth Chang. 2019, 50, 201-221. [CrossRef]

29. Yan, X.; Dong, D.; He, S.; Webster, C. Examining Trans-Provincial Diagnosis of Rare Diseases in China: The Importance of Healthcare Resource Distribution and Patient Mobility. Sustainability 2020, 12, 5444. [CrossRef]

30. Guo, Y.; Qiao, W. Rural Migration and Urbanization in China: Historical Evolution and Coupling Pattern. Sustainability 2020, 12, 7307. [CrossRef]

31. Li, D.; Weng, Y.; Yang, X.; Zhao, K. Self-Deprecation or Self-Sufficient? Discrimination and Income Aspirations in Urban Labour Market Sustainable Development. Sustainability 2019, 11, 6278. [CrossRef]

32. Wu, Y.; Wen, J. Fear of crime among Chinese immigrants in Metro-Detroit. Crime Law Soc. Chang. 2014, 61, 495-515. [CrossRef]

33. Appau, S.; Churchill, S.A.; Smyth, R.; Zhang, Q. Social Capital Inequality and Subjective Wellbeing of Older Chinese. Soc. Indic. Res. 2020, 1-23. [CrossRef]

34. Huo, X. Rural migrant workers' civilization and political participation. Exploration 2007, 109, 41-46.

35. Solinger, D.J. The creation of a new underclass in China and its implications. Environ. Urban 2006, 18, 177-193. [CrossRef]

36. Wu, F. Neighborhood attachment, social participation, and willingness to stay in China's low-income communities. Urban Aff. Rev. 2012, 48, 547-570. [CrossRef]

37. Liu, Y.; He, S.; Wu, F.; Webster, C. Urban villages under China's rapid urbanization: Unregulated assets and transitional neighbourhoods. Habitat Int. 2010, 34, 135-144. [CrossRef]

38. Zhou, M.; Cai, G. Trapped in neglected corners of a booming metropolis: Residential patterns and marginalization of migrant workers in Guangzhou. Urban China Trans. 2008, 226-249. [CrossRef]

39. Hale, C. Fear of crime: A review of the literature. Int. Rev. Vict. 1996, 4, 79-150. [CrossRef]

40. Özaşçılar, M.; Ziyalar, N. Unraveling the determinants of fear of crime among men and women in Istanbul: Examining the impact of perceived risk and fear of sexual assault. Int. J. Offender Ther. Comp. Criminol. 2017, 61, 993-1010. [CrossRef]

41. Pryce, D.K.; Wilson, G.; Fuller, K. Gender, age, crime victimization, and fear of crime: Findings from a sample of Kenyan College students. Secur. J. 2018, 31, 821-840. [CrossRef]

42. Vauclair, C.; Bratanova, B. Income inequality and fear of crime across the European region. Eur. J. Criminol. 2017, 14, 221-241. [CrossRef] [PubMed]

43. Kujala, P.; Kallio, J.; Niemelä, M. Income inequality, poverty, and fear of crime in Europe. Cross-Cult. Res. 2019, 53, 163-185. [CrossRef]

44. Allen Furr, L.; Mark Austin, D.; Cribbs, S.E.; Smoger, S.H. The effects of neighborhood satisfaction on perception of safety among refugees from the former Soviet Union. Sociol. Spectrum 2005, 25, 519-537. [CrossRef]

45. Ackah, Y. Fear of crime among an immigrant population in the Washington, DC metropolitan area. J. Black Stud. 2000, 30, 553-573. [CrossRef]

46. Hodgkinson, T.; Gately, N.; McCue, J.; Shuhad, A.; Corrado, R.R.; Andresen, M.A. Fear of crime in an island paradise: Examining the generalizability of key theoretical constructs in the Maldivian context. Int. Crim. Justice Rev. 2017, 27, 108-125. [CrossRef]

47. Abbott, J.; McGrath, S.A. The effect of victimization severity on perceived risk of victimization: Analyses using an international sample. Victims Offenders 2017, 12, 587-609. [CrossRef]

48. Rühs, F.; Greve, W.; Kappes, C. Coping with criminal victimization and fear of crime: The protective role of accommodative self-regulation. Legal Criminol. Psych. 2017, 22, 359-377. [CrossRef]

49. Singer, A.J.; Chouhy, C.; Lehmann, P.S.; Walzak, J.N.; Gertz, M.; Biglin, S. Victimization, fear of crime, and trust in criminal justice institutions: A cross-national analysis. Crime Delinq. 2019, 65, 822-844. [CrossRef]

50. Dowler, K. Justice: The relationship between fear of crime, punitive. J. Crim. Justice Pop. Cult. 2003, 10, 109-126. 
51. Henson, B.; Reyns, B.W.; Fisher, B.S. Fear of crime online? Examining the effect of risk, previous victimization, and exposure on fear of online interpersonal victimization. J. Contemp. Crim. Justice 2013, 29, 475-497. [CrossRef]

52. Chadee, D.; Ng Ying, N.K.; Chadee, M.; Heath, L. Fear of crime: The influence of general fear, risk, and time perspective. J. Interpers. Violence 2019, 34, 1224-1246. [CrossRef] [PubMed]

53. Kupchik, A.; Bracy, N.L. The news media on school crime and violence: Constructing dangerousness and fueling fear. Youth Violence Juv. J. 2009, 7, 136-155. [CrossRef]

54. Tseloni, A.; Zarafonitou, C. Fear of crime and victimization: A multivariate multilevel analysis of competing measurements. Eur. J. Criminol. 2008, 5, 387-409. [CrossRef]

55. Tchinda, P.E.; Kim, S. The Paradox of "Eyes on the Street": Pedestrian Density and Fear of Crime in Yaoundé, Cameroon. Sustainability 2020, 12, 5300. [CrossRef]

56. Lis, A.; Pardela, A.; Iwankowski, P. Impact of vegetation on perceived safety and preference in city parks. Sustainability 2019, 11, 6324. [CrossRef]

57. Cho, Y.; Jeong, H.; Choi, A.; Sung, M. Design of a connected security lighting system for pedestrian safety in smart cities. Sustainability 2019, 11, 1308. [CrossRef]

58. Lee, J.S.; Park, S.; Jung, S. Effect of crime prevention through environmental design (CPTED) measures on active living and fear of crime. Sustainability 2016, 8, 872. [CrossRef]

59. Wilson, J.Q.; Kelling, G.L. Broken windows. Atl. Mon. 1982, 249, $29-38$.

60. Sampson, R.J.; Raudenbush, S.W. Seeing disorder: Neighborhood stigma and the social construction of "broken windows". Soc. Psychol. Quart. 2004, 67, 319-342. [CrossRef]

61. Woldoff, R.A. Emphasizing fear of crime in models of neighborhood social disorganization. Crime Prev. Commun. Saf. 2006, 8, 228-247. [CrossRef]

62. Porter, J.R.; Rader, N.E.; Cossman, J.S. Social disorganization and neighborhood fear: Examining the intersection of individual, community, and county characteristics. Am. J. Crim. Justice 2012, 37, 229-245. [CrossRef]

63. Helfgott, J.B.P.W. Misdemeanor arrests and community perceptions of fear of crime in Seattle. J. Crim. Justice 2020, 69, 101695. [CrossRef]

64. Roccato, M.; Russo, S.; Vieno, A. Perceived community disorder moderates the relation between victimization and fear of crime. J. Commun. Psychol. 2011, 39, 884-888. [CrossRef]

65. Ross, C.E.; Jang, S.J. Neighborhood disorder, fear, and mistrust: The buffering role of social ties with neighbors. Am. J. Commun. Psychol. 2000, 28, 401-420. [CrossRef]

66. Barni, D.; Vieno, A.; Roccato, M.; Russo, S. Basic personal values, the country's crime rate and the fear of crime. Soc. Indic. Res. 2016, 129, 1057-1074. [CrossRef]

67. Hanslmaier, M. Crime, fear and subjective well-being: How victimization and street crime affect fear and life satisfaction. Eur. J. Criminol. 2013, 10, 515-533. [CrossRef]

68. Adams, R.E.; Serpe, R.T. Social integration, fear of crime, and life satisfaction. Sociol. Perspect. 2000, 43, 605-629. [CrossRef]

69. Gibson, C.L.; Zhao, J.; Lovrich, N.P.; Gaffney, M.J. Social integration, individual perceptions of collective efficacy, and fear of crime in three cities. Justice Q. 2002, 19, 537-564. [CrossRef]

70. Wikström, P.H.; Dolmén, L. Urbanisation, neighbourhood social integration, informal social control, minor social disorder, victimisation and fear of crime. Int. Rev. Vict. 2001, 8, 121-140. [CrossRef]

71. Sampson, R.J.; Raudenbush, S.W.; Earls, F. Neighborhoods and violent crime: A multilevel study of collective efficacy. Science 1997, 277, 918-924. [CrossRef] [PubMed]

72. Yuan, Y.; McNeeley, S. Social ties, collective efficacy, and crime-specific fear in Seattle neighborhoods. Victims Offenders 2017, 12, 90-112. [CrossRef]

73. Roh, S.; Oliver, W.M. Effects of community policing upon fear of crime. Polic. Int. J. Police Strateg. Manag. 2005, 28, 670-683. [CrossRef]

74. Maguire, E.R.; Johnson, D.; Kuhns, J.B.; Apostolos, R. The effects of community policing on fear of crime and perceived safety: Findings from a pilot project in Trinidad and Tobago. Polic. Soc. 2017, 29, 491-510. [CrossRef]

75. Alda, E.; Bennett, R.R.; Morabito, M.S. Confidence in the police and the fear of crime in the developing world. Polic. Int. J. Police Strateg. Manag. 2017, 40, 366-379. [CrossRef] 
76. Liu, Y.; Zhang, F.; Liu, Y.; Li, Z.; Wu, F. The effect of neighbourhood social ties on migrants' subjective wellbeing in Chinese cities. Habitat Int. 2017, 66, 86-94. [CrossRef]

77. Shevky, E.; Williams, M. The Social Areas of Los Angeles, Analysis and Typology; Publication for John Randolph Haynes and Dora Haynes Foundation; University of California: Los Angeles, CA, USA, 1949.

78. Paternoster, R.; Brame, R.; Mazerolle, P.; Piquero, A. Using the correct statistical test for the equality of regression coefficients. Criminology 1998, 36, 859-866. [CrossRef]

79. Rountree, P.W.; Land, K.C. Burglary victimization, perceptions of crime risk, and routine activities: A multilevel analysis across Seattle neighborhoods and census tracts. J. Res. Crime Delinq. 1996, 33, 147-180. [CrossRef]

80. Bolger, M.A.; Bolger, P.C. Predicting fear of crime: Results from a community survey of a small city. Am. J. Crim. Justice 2019, 44, 334-351. [CrossRef]

81. Niu, P. Policy-Making and Deliberation in Urban Village Regeneration in China. Ph.D. Thesis, University of Sheffield, Sheffield, UK, 2019.

82. Brunton-Smith, I. Untangling the relationship between fear of crime and perceptions of disorder: Evidence from a longitudinal study of young people in England and Wales. Br. J. Criminol. 2011, 51, 885-899. [CrossRef]

Publisher's Note: MDPI stays neutral with regard to jurisdictional claims in published maps and institutional affiliations.

(C) 2020 by the authors. Licensee MDPI, Basel, Switzerland. This article is an open access article distributed under the terms and conditions of the Creative Commons Attribution (CC BY) license (http://creativecommons.org/licenses/by/4.0/). 